
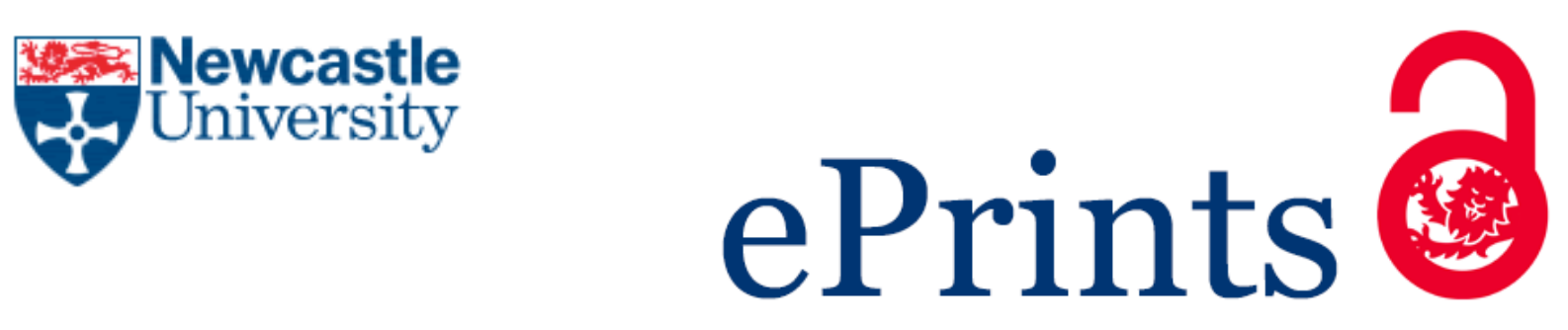

Butler C. Being appropriately professional: the interaction between professionalism, ICT and knowledge transfer. New Technology, Work and Employment 2016, 31(2), 132-145.

\title{
Copyright:
}

This is the peer reviewed version of the following article: [Butler C. Being appropriately professional: the interaction between professionalism, ICT and knowledge transfer. New Technology, Work and Employment 2016, 31(2), 132-145.], which has been published in final form at http://dx.doi.org/10.1111/ntwe.12064. This article may be used for non-commercial purposes in accordance with Wiley Terms and Conditions for Self-Archiving.

DOI link to article:

http://dx.doi.org/10.1111/ntwe.12064

Date deposited:

$25 / 07 / 2016$

Embargo release date:

01 July 2018 


\section{Being appropriately professional: the interaction between professionalism, ICT and knowledge transfer}

This article examines how professionalism impacts on the interaction and knowledge transfer of professionals within open plan workspaces and between distributed workplaces when using ICT. Knowledge is key to the system of professions and the power of professionals. At the same time, professional work requires professionals to behave in an appropriate and professional-like manner, and this includes sharing knowledge with colleagues. Yet, the ideology of professionalism is changing. Alongside, professionals are working differently, including across distributed workplaces and often interacting via ICT. These shifting contexts make understanding the interaction between professionalism, knowledge transfer and ICT crucial. Drawing on Goffman's work, particularly his exposition of interaction rituals, interviews with accountants reveal that when using ICT, the professional framework of interaction what can be said, who has the right to speak and who is the audience - meets appropriateness in sometimes contradictory ways, potentially limiting the growth and propagation of knowledge.

Keywords: distributed workplaces, flexible working, Goffman, ICT, knowledge transfer, knowledge workers, professions, professionalism 


\section{Introduction}

Professionals rely on the professionalism of other professionals to do their job; amongst other things, they need colleagues to share knowledge (Blackler, 1993). Access to and control of knowledge is key to the system of professions (Abbott, 1988) and depending on their role and career stage, professionals will have varying knowledge needs: gaining, maintaining or influencing knowledge might be a priority (Suddaby and Viale, 2011). As a result, the system of professions is infused with social negotiation (Van Maanen and Schein, 1979) and knowledge evaluation (Empson, 2001) where professionals are confronted with issues of ego (Robertson and Swan, 1998), trust and autonomy (Paton et al., 2013). Navigating what it is to 'be professional' within the system of professions is informed by knowing what is appropriate behaviour (Van Maanen and Schein, 1979). Appropriateness is learnt through a process of becoming a professional (Ibarra, 1999): affecting how people undertake their role (Larson, 1979) and engage with colleagues (Dent and Whitehead, 2002). Yet, the concept of professionalism is changing: reflecting a shifting dynamic between managerial control and professional ideology (Evetts, 2013). At the same time, professionals are working differently within diverse spaces and places - and often interacting through information and communication technology (ICT). As a result of the need to better understand this changing context, this article examines how professionalism impacts on the interaction and knowledge transfer of professionals within open plan workspaces and between distributed workplaces when using ICT.

A public sector accountancy department in the UK provides a fruitful context in which to examine this issue because they were simultaneously subject to two changes in their working arrangements - a new open plan office plus hybrid working (office and home) - and increasingly used ICT, specifically email, to communicate with colleagues. Differing from much prior research of hybrid working, all members of the accountancy department, irrespective of role or grade, were subject to the new working arrangements and worked off-site for at least two days per week. As a result, this study offers an interesting prospect in exploring the relations between professionalism, ICT and knowledge transfer for professionals in different roles and career stages.

The article argues that a changed workspace and the increase in communication through ICT, alters the way in which professionalism is enacted by both junior and senior staff. The research finds that when mediated through ICT, the framework of interaction - what can be 
said, who has a right to speak and who is the audience - meets appropriateness in sometimes contradictory ways: potentially limiting the growth and propagation of knowledge. In developing its argument, the article is divided into six further parts. Drawing on the literature of professions and the work of Erving Goffman, the next section considers the nature of professions and the constitution of a professional performance. Section 3 reviews the literature on changing workspaces, examining the difference that space makes to how work is performed and experienced. Section 4 considers knowledge, ICT and professional work. Section 5 introduces the study that is at the centre of this article and Section 6 discusses the findings. The article concludes by arguing that a focus on changing workspaces, and the increased use of ICT to connect workers, needs also to consider how this interacts with the notion of what it is to be professional.

\section{Professions and professionalism}

Early studies of the professions highlighted a number of key features including a systematic and abstract knowledge base; formal, staged training programme; and system of self-regulation (Durkheim, 1957). Focusing on the sociology of the professions, Goode (1957) observed that members are typically involved in the selection and socialisation of trainees; and often develop common values, along with a common language. This early work came under fire for overlooking (or ignoring) the in-built power dimensions, with Johnson (1972) arguing that a profession is less an inherent feature of an occupation, rather it is more a way of controlling and organising; one which ensures social closure and emphasises the status in and of membership. More recently, it has been suggested that the adoption of the term professional (as part of what is described as the 'professional project') is now institutionalised: it denotes personal credentials and expertise and, ultimately, the delivery of a product or service that is of value (Freidson, 2001). As such, research has moved away from the examination of the classification and/or dominance of particular professions to the way in which professionals gain, claim and maintain their relatively privileged position in society (Faulconbridge and Muzio, 2008; Scott, 2008; Suddaby et al., 2009). The study of professionalism as a way of being and doing has led to the consideration of the performative aspects (Dent and Whitehead, 2002) and the way in which professionalism is performed.

Entrance to a profession (or a professionalised occupation) involves crossing into what can be unfamiliar territory (Ibarra, 1999): the community of practice (Wenger, 1998). Originally conceived of as a spontaneous, networked group of likeminded individuals, a community of 
practice is said to share understandings and unite in actions and meanings (Lave and Wenger, 1991). The extent to which the concept applies within organisational contexts is subject to debate (Swan et al., 2002); still, its use as a tool of rhetoric, seeking to engage and/or control workers, means it remains firmly in the management lexicon (Fox, 2000). Yet, given the inculcation of members as they cross into a profession - and enter accounting practice, for example - the concept is germane. Joining a professional community of practice is typically a lengthy process of becoming: whether medic (Pratt et al., 2006), accountant (Anderson-Gough et al., 2000) or software developer (Marks and Scholarios, 2007), a new professional self is constructed (Ibarra, 1999). The process of professionalisation requires boundary work (Star and Griesemer, 1989) whereby staged routes of entry act as demarcations - excluding those who do not 'fit' - but also acting as conditions for bridging, exchanging and communicating appropriateness (Van Maanen and Schein, 1979), as well as knowledge (Ibarra, 1999).

In his exposition of the importance of symbolic action in everyday life, Goffman (1959; 1963b) contends that people display appropriateness by covering those aspects of themselves that may be stigmatised within the community with the aim of passing as a legitimate member. For Goffman (1959) these performances take place in regions (or stages). Front regions are where the actor considers him or herself in view of the audience and behaves according to his or her role. Back regions, on the other hand, are considered out of view of the audience and are where, amongst other things, training takes place, props are created and performances rehearsed. The boundaries between front and back regions need not be physical; speaking to a colleague privately during a team meeting creates a separate region, albeit temporarily.

Much of Goffman's $(1955 ; 1963 a ; 1972 b)$ work explores the interaction rituals enacted to maintain face in front regions. Face is the positive social value that people wish to uphold during their interactive events. The actions carried out by a person to make whatever he or she is doing consistent with face is called face-work. The success, or otherwise, of face-work has implications in representing the position of an actor - such as expert, trainee or mentor. Alongside, the response of the audience situates each actor - confirming his or her position as expert, for example - and this constructs the tacitly-agreed interactional framework. Furthermore, to maintain the appropriateness of the interactional framework, people must take into account the face needs of their interactants.

As a result, the interactional framework is dynamic and developed during interaction; denoting the status, rules of engagement and roles of involvement of each party. At the workplace, interaction between actors is further complicated by being nested within a context 
of organisational roles that might involve, for example, authority and hierarchy (Van Maanen and Schein, 1979). Accordingly, and in Goffman's terms, the process of becoming a member of a professional community includes gaining an appreciation of the legitimacy in and of communication (what can be said and what is heard, considering appropriateness); and the enactment of roles (who has the right to speak and who is the audience). As such, the process of professionalisation develops an individual's understanding of what constitutes an appropriate professional interactional framework.

\section{Professional communities and knowledge transfer}

The requirements of a professional community are ever-changing - reflecting legal requirements, technological advancements or policy developments - therefore, membership requires ongoing maintenance work and the transfer of knowledge between members, old and new (Wenger, 1998). This maintenance work might come under the umbrella of continuing professional development, where knowledge transfer is achieved by attending accredited courses or, informally, through engaging with colleagues. Yet, before addressing its transfer, there are considerations of what constitutes knowledge, where it resides and how and if it can be managed to create organisational value (Hazlett et al., 2005; McAdam and McCreedy, 2000). The difficulty in tackling these questions stems from the character of knowledge and whether knowledge is regarded as predominantly tacit or explicit in nature. Tacit knowledge is considered inherently difficult to transfer because it cannot be fully articulated through written or verbal communication; instead, it is gained through experience (Nonaka and Takeuchi, 1995). Yet, explicit knowledge is no less difficult to transfer; it is often context-specific and requires an appreciation of the dynamics of resources and environment before it can be learned and usefully applied within the relevant work community (Brown and Duguid, 1991).

Given the increasing complexity of work, distributed workplaces and the rise in collaborative working, the mechanisms that surround knowledge transfer have been the subject of much research. Studies suggest that being in close proximity to co-workers - sharing a social space - maximises learning, of both tacit and explicit knowledge (Wenger, 1998). Colleagues learn as a result of being involved in the day-to-day activities of the work setting (Lave and Wenger, 1991; Wenger, 1998); this, in turn, aids the performance and coordination of work (Kiesler and Cummings, 2002). Indeed, in the 1970s open plan workspaces were introduced in an attempt to maximise the benefits of colleagues sharing the same workspace. The results, however, have been mixed: the diminution of barriers increases connectivity and aids 
knowledge transfer for some workers, but for others open plan workspaces decreases job satisfaction, instils a sense of social control and reduces creativity (Felstead et al., 2005; Marans and Spreckelmeyer, 1982; Zalesny and Farace, 1987). Following their study of open plan working by academics, Baldry and Barnes (2012) highlight the advantages (reflecting the managerialism that accompanies the connectivity discourse) and then note that gaining privacy for meetings or 'simply' thinking is often problematic (Felstead et al., 2005; Zalesny and Farace, 1987).

In stark contrast, for those workers who are off-site or home-based, for some or all of the time, studies have identified that excessive privacy - in fact, isolation - is a common concern (Baruch, 2000; Lai and Burchell, 2008; Whittle and Mueller, 2009). Nonetheless, those offered the option to work from home typically have this framed as an endorsement of their value to the firm: highlighting the autonomy and flexibility that is afforded (Felstead et al., 2002; Ruiz and Walling, 2005). Yet, employees do not always view remote working as a preferential option (Kurland and Egan, 1999). Workers may have extended periods of time when they do not meet their colleagues (Brown and O'Hara, 2003); as a result, newcomers find team integration and identification more difficult (Bosch-Sijtsema et al., 2010; Lai and Burchell, 2008) and more established team members have concerns of a lack of presence for their career development: out of sight, out of mind (Baruch, 2000). Aligning with Lave and Wenger (1991), Halford (2005:29) argues that whether for newcomers or established workers, one of the main challenges of distributed working is the "loss of the casual inputs derived from co-location: overhearing and overseeing - the chance synergy' where workers pick up valuable knowledge almost 'by accident'.

\section{Professionals, knowledge transfer and ICT}

The negotiation of what constitutes knowledge - what is known to the community - and who engages in the surrounding processes is integral to the system of professions and influence of professionals (Abbott, 1988; Scott, 2008). Professionals are said to withhold sharing what they know because of concerns around the loss of their intellectual capital (Addicott et al., 2007; Donnelly, 2011), with professional norms influencing this behaviour (Haas and Park, 2010). Yet, evidently, professional knowledge is not static: drawing on their expertise and social capital, professionals introduce new actors and new knowledge; and this shifts the boundaries of the profession and recreates what constitutes valuable knowledge (Suddaby and Viale, 2011). The evaluation of worthiness is, as everything else, up for debate: professionals with a 
high level of tacit knowledge view explicit knowledge as less valuable and vice versa, which can result in struggles of knowledge primacy (Empson, 2001). Furthermore, the rise of corporate professionalisation, and the 'management' and evaluation of knowledge by firms, has heightened the tension between professionals and managers. This tension is considered to be as a result of two main issues: first, modes of organising that emphasise the collective value of knowledge clash with individual notions of power (Robertson and Swan, 1998) and, second, the potential loss of professional autonomy to the spectre of management (Faulconbridge and Muzio, 2008; Paton et al., 2013). As a result of this body of work, there are concerns about the extent to which managing professional knowledge is feasible (let alone, desirable).

Considerations of the influence of ICT on knowledge management tend to privilege either the materiality of ICT (its functionality) or the social (how people regard ICT) (Leonardi and Barley, 2008). Yet, both sides of the materiality-social debate largely agree that to better understand ICT enabled workplaces requires the exploration of the interaction between people and technology (Orlikowski, 2002). Adopting this interactive approach means considering workers' practices and perceptions; and, when in their work role, what 'technology lets users do, what it does not let them do' (Leonardi and Barley, 2008:164). Beyond issues of power and intellectual capital, there are a number of factors that influence the way in which professionals interact with ICT. For example, prioritising whether to spend time entering information into a knowledge management system or on (fee earning) client-facing work (Boussebaa et al., 2014). Alongside, there are challenges related to the incompatibility of the ICT system with the nature of knowledge, whether explicit or tacit (Lai and Burchell, 2008; Trusson et al., 2014). This incompatibility has led Hislop (2002:165) to question if knowledge management via ICT is 'mission impossible', given that knowledge is 'embodied in human brains and bodies and is embedded in organizational routines, practices and contexts'.

Likewise, Zuboff (1988) argues that it is important to recognise that the way in which people make sense of informational cues, and transform it into usable knowledge, is not necessarily changed as a result of ICT. Consequently, and returning to Goffman's interactional framework, Zuboff contends that the processes of deduction, interpretation and management of knowledge through ICT must be considered alongside workers' everyday practices and the way in which colleagues engage with each other. It is the matter of knowledge management and ICT in a professional context that offers the backdrop for this research. As such, the aim of this study is to examine how professionalism impacts on the interaction and knowledge transfer of 
professionals within open plan workspaces and between distributed workplaces when using ICT.

\section{The Study}

The study took place at a UK public sector accounting department (pseudonym PACT). Following the 2007/08 financial crisis, PACT sought to reduce its operating costs. This exercise resulted in the reconfiguration of work sites, with the result that the majority of employees in the accounting department were relocated from their city location to an out-of-town site. The new accommodation differed from the old worksite in two key ways. First, the office was open plan. Second, there was desk space available for (typically) around half of the members of each accounting team at any one time. Those not allocated a desk for the day were required to work at home with the use of ICT: laptop computers and mobile phones. Differing from the firms that have been the subject of a number of prior studies, PACT implemented hybrid working for all members of the accounting department, irrespective of role or grade, with all staff being required to work off-site for at least one day per week. In practice, the majority of staff were based in the office for two or three days per week. This arrangement was laid out on a rota, whereby staff were allocated a desk for set days of the week.

Field work took place in spring 2013 and data were collected via a) individual interviews, b) informal discussions and c) observational field notes. Semi-structured interviews took place in a private setting at PACT and lasted from 45 to $95 \mathrm{~min}$, with the average being one hour. Participants were accounting practitioners, six women and seven men, who were aged between 26 and 53 years of age and had worked in public sector accounting from 6 to 32 years. Five of the interviewees had team management responsibilities. Seven were fully qualified chartered accountants, six were part-qualified with three of these in their final year of study. Beyond background questions relating to prior work experience and career choice, the interview questions invited participants to talk about their work experiences and relationships with colleagues, including the impact of any recent changes in their role, team or organisation. Interviews were audio recorded, transcribed, anonymised and interviewees given a pseudonym.

Along with the individual interviews, the visit to PACT allowed for informal discussions with other members of the accounting department; and observation of the workspace (for example, artefacts, office layout and acoustics) and of the use of space more generally (such as the movement between desk spaces, use of 'free' spaces, level of interaction between and across teams). Thus, notes of the informal discussions and observational field logs were taken, 
representing a supplementary data set. In analysing the whole data set, issues and ideas were coded to thematic nodes in NVivo 10. The nodes were created, amended, deleted and/or merged in a way that responded to the data and helped to make sense of them (Miles and Huberman, 1994). Data analysis identified that home working resulted in social isolation and difficulties in achieving work-life balance, as prior work (Baruch, 2000; Lai and Burchell, 2008; Whittle and Mueller, 2009); however, this article will focus on the data that spoke to the effect of the new working arrangements on interaction, knowledge transfer and the use of ICT. This focus led to the emergence of three themes, which will be used to structure the discussion: a) looking like a professional, b) demonstrating professionalism and c) managing the knowledge of the profession.

\section{Looking like a professional}

When discussing the recent changes at PACT, the majority of interviewees said that the new open plan office had altered their behaviour. Specifically, they described the openness as 'preventing' (Betty) them from approaching colleagues and that, as a result, communication amongst colleagues in the office had 'dramatically reduced' (George). When asked why their behaviour had changed, they spoke in terms of visibility (Felstead et al., 2003), as David explains:

If you can see them at the end of the room, you can maybe see they're busy or something you wouldn't think of walking to see them. As well as that, you don't want to look as if you're not working. (David)

Irrespective of seniority, grade or role, interviewees consistently reported that the open plan workspace was not an appropriate place for conversation. In particular, they described being concerned of giving the 'wrong impression' if they 'had time to chat' (Mary), even about a work-related issue. As a result, they would forego moving to talk to colleagues within the office space. When on-site during data collection, this immobility was noticeable: movement between the banks of desks within the office was rare; talking across the desks without moving out of the seat was observed, although this was typically whispered. As Robert remarked: 'it's all like muffled noise'.

When they wished to speak to a colleague about a service delivery issue, an ongoing project or the treatment of an accounting item, the accountants spoke of sending an email to arrange to meet. Of interest is, first, the regularity with which participants said they did this and, second, how these meetings were spoken of: within grades, but not amongst teams. Senior officers 
described emailing other senior colleagues (six or seven times a day on average) to meet on a different floor of the building, which resulted in 'fewer chats than we used to have in front of the team about what's going on and what we need to do' (Emma). Similarly, early career accountants spoke of emailing other early career colleagues to meet in a different space to ask for advice on a work issue, with the most common place being the printing area.

This belief that talking to colleagues in the office is in some way 'wrong' was a recurring theme, and suggests that the open plan office is conceptualised as a front region with colleagues, who were once fellow actors, now being given the role of audience. Colleagues, when considered as audience, are not appropriate witnesses to the rehearsal of performances. Likewise, training takes place in back regions: beyond the audience's view. Importantly, this new actor-audience role configuration produces the accountants' interactional framework, that is - what should be said (if, indeed, anything should be said), to whom and in front of whom.

The accountants' response is evidence of the transparency paradox - whereby observability induces 'those being observed to conceal their activities through codes and other costly means' (Bernstein, 2012:205). However, the social control of workspace (Zalesny and Farace, 1987) is accompanied by professional control (Fournier, 1999); and the need to gain and maintain knowledge dominates, legitimising this conduct: making the region creating behaviour 'right'. In this matter, ICT acts as an enabler, helping the accountants to construct different regions and facilitate the transfer of knowledge - albeit pursued knowledge on specific issues. Yet, the manner in which they negotiate the workspace maintains the gradated interactional framework. Furthermore, besides the loss of accidental knowledge transfer that is likely to result from these back region conversations - both within teams and between grades - the 'costly means' in this study relate to the time and effort the accountants spend on impression management.

\section{Demonstrating professionalism}

Beyond the open plan workspace, participants described how ICT helped them in demonstrating their professionalism to budget managers and project partners. The new working arrangements led to all staff having their desktop computers replaced with laptops. The laptops were connected to the financial ledger and interviewees regularly commented on the usefulness of having the ledger with them when they attended meetings, as Oliver notes:

It helps to be able to show the ledger, you know spend, commitments and especially projections, when you meet people. Print-outs [of the ledger] didn't have the same influence. 
I can say 'look, this is where you are, this is what you've committed and this is what has been projected.' (Oliver)

Here, Oliver talked of ICT as a professional prop; an artefact that offers influence. Pinch and Bijker (1984) argue that, via a process of social construction, a group's norms and values affect the meaning given to a technological artefact. For the accountants at PACT, this process appears reciprocal: the ICT also adds value to the meaning of being professional, it is a mechanism for face-work. Alongside, the way in which respondents' described using the ICT with budget managers appears to create a new actor category - an accountant who is 'really professional' - and, just like Navis and Glynn's (2010) study of web bloggers, the accountants draw on established values along with new values to gain legitimacy. For example, Fiona commented on her use of ICT as a dynamic forecasting tool that enabled her to showcase her professional knowledge and expertise, especially in the relatively new area of multi-funded projects. In combination with the accounting standards, she explained that the often precise conditions of grant funding impact on the costing of different service delivery options. Here Fiona described the ICT as an influencing and legitimating artefact:

Having the laptop with me [during meetings] has certainly helped our managers to appreciate the importance of accounting: why it matters that things are done right - yes - but also how accounting supports services to deliver services. We have more and more projects that are grant funded and the way you account for aspects of the project can differ. Sometimes, you know, the conditions of the grant are so exacting and when they are in combination, I can demonstrate, illustrate how the differences play out for services. I can build up the [financial] profile and we can change elements and see how it looks. Yeah, the laptop has made a real difference. It shows how I, and the team, give a really professional level of support. (Fiona)

Like Fiona, when the majority of respondents spoke of the use of ICT during face-to-face meetings, the technology seemingly legitimised the interaction. For these accountants, their notion of professionalism is grounded in the display of established knowledge that has a 'foundation in abstract concepts and formal learning' (Freidson, 2001:35); the application of this abstract knowledge is made real through its effect on the financial forecasting, and is demonstrated through ICT. In addition, the technology also furthered knowledge by facilitating a different conversation with budget managers:

[When using the laptop] it's like they [budget managers] can see what we know, what we can do and why it's useful to talk to us. Plus it helps to build a good working relationship because they see the impact of their understanding of service delivery and they understand, sometimes for the first time, why we need to know, why we ask the questions we do. (David) 
David's remark is representative with many interviewees speaking of conversation and learning, but further analysis indicated that this knowledge transfer is one-way. Specifically, knowledge of the accounting profession is maintained: the ICT 'shows' and budget managers can 'see', but it is the budget managers that talk and the accountants who build their knowledge. As a consequence, accounting knowledge was considered to be made more professional (read, accessible) when integrated with service knowledge and demonstrated via ICT. This accessibility was achieved whilst staying within role and without the 'loss' of the accountants' knowledge, or power (Robertson and Swan, 1998). This role enactment reflects the ability of professionals to professionalise and, simultaneously, hold onto their interests (Faulconbridge and Muzio, 2008). Furthermore, and importantly, professional appropriateness is maintained when the amalgam of knowledge - accounting and service - is assimilated into the conversation. More specifically, the professional interactional framework is appropriate because it took into account the face needs of both parties: the budget managers understood the importance of their knowledge and the accountants' knowledge was given added status.

\section{Managing the knowledge of the profession}

To look the part in front of colleagues and demonstrate professionalism to others, participants' spoke of the importance of gaining and maintaining knowledge. They all considered that this was made more challenging because of the new working arrangements. Office-based workers often resent having to pick up tasks that those based at home are able to avoid (Felstead et al., 2003), but this differed markedly here. The majority of early career accountants spoke of being keen to be at the office because this allowed them to take on additional tasks and grow their knowledge. When describing the practices of one manager, Mary said:

He always seems to come to our team rather than any other team [...] but I enjoy doing it because it's sort of extra work that gives you more experience and helps you develop. (Mary)

Beyond the accidental learning described above, plugging specific knowledge gaps was also considered to be more complicated now, as Louise highlights:

When we were all sitting together you could throw out a question about something you were stuck on and we'd all have a chat about it and it would be 'right that's the way we're going to do it'. But now, at home, I think 'right, who can I ask about this now? who can I contact?'. I can't just throw it out there and someone will come back with 'well I did it this way' and 'I did it this way', you know. (Louise) 
The challenge of gaining knowledge was reported by early career accountants and senior officers; however, it was those who occupied more senior roles who described experiencing the greatest difficulties following the introduction of the new working arrangements. As a team leader, Hugo described a 'tricky problem' in relation to his own knowledge management. The problem was echoed by a number of interviewees and related to communicating via ICT when working remotely; despite its trickiness, it was simply put:

I can't email queries on issues - technical or policy issues - that I should know about. (Hugo) Many of his team have more experience and, he admitted sheepishly, more knowledge than him and given that he is in a senior position, he continued:

How can I ask questions on what are probably simple things without looking ... well ... like I'm lacking? [because] knowledge moves up as well as down, doesn't it? (Hugo)

For those established in a profession, being able to claim, maintain and/or gain knowledge is vital (Faulconbridge and Muzio, 2008; Scott, 2008; Suddaby et al., 2009) and Hugo described being hampered in gaining knowledge because he is unable to ask questions 'in an oblique way' through email. By way of explanation, he relayed one of the techniques he used to employ to ask questions of his colleagues when based at the previous worksite:

I [would] suggest we bounce ideas around - that way I learn without asking. (Hugo) In Forms of Talk, Goffman (1981) contends that deliberate ambiguities during interpersonal exchanges can be functional: upholding orderly communication, preserving face and, thus, maintaining an appropriate interactional framework. The associated communicative techniques might involve conversational game playing, as Hugo's approach; the simulation of misunderstanding; or, asking a series of questions when the speaker is seeking a response to one specific question only, but he or she does not want this to be known. Goffman calls these buried queries or speaker's dodges. In Hugo's case, his dodges were directed toward him gaining access to colleagues' knowledge, but without losing face.

In the same vein, when Louise spoke about being 'stuck' on a problem when working at home she described deliberating: 'right, who can I ask about this now? who can I contact?' She said that she had one or two colleagues that she would typically email, saying that she trusted them to respond without making her 'feel stupid for asking'. This comment is strikingly different from her earlier remark of being happy to 'throw out a question' when sitting amongst her team. 
Likewise, when discussing the next steps in developing the ICT at PACT, Ivor described an instant messenger service. Echoing the issues raised by Hugo and Louise, he said:

It's an online system, you get to see the person you're speaking to, which can help people connect. Also, it's not held anywhere [...] The conversation isn't recorded anywhere and so when I was telling them [colleagues] about it, I said that they can talk in the same way as they would if they were in the office. I know a lot of them don't like using email. I'm not keen on it either, really. If I want to understand something, ask someone something you know, I wouldn't use email for that. That's why this messenger system, I think, would work. There's a group setting for discussing ideas, but it's a way off yet. I mean, it's available, but it's way off being used like that, unfortunately. (Ivor)

It is of interest to observe Ivor's comment that when he wants to 'ask something' he 'wouldn't use email for that'. He went onto remark that 'people seem to save up questions 'til they're in the office' and that he hopes that the instant messenger system might help resolve the issue.

In each of these accounts, the development of what is considered to be an appropriate, professional interaction is altered by the intervening ICT interface. The enactment of roles speaker, hearer and audience - and what can be said while in role shifts, and in sometimes contradictory ways, limiting the development and propagation of knowledge.

\section{Conclusions}

This article contributes to our understanding of how professionalism impacts on the interaction and knowledge transfer of professionals within open plan workspaces and between distributed workplaces when using ICT. The professionalisation of workers is endemic (Freidson, 2001). The process of becoming a professional is one of exchanging and inculcating understandings and meaning within a community of practice (Lave and Wenger, 1991); and being imbued with the notion of appropriateness, of both knowledge and behaviour (Ibarra, 1999; Van Maanen and Schein, 1979). At the interpersonal level, appropriate behaviour shapes and is shaped by a complex and dynamic interactional framework, which is social and political (Goffman, 1959; Goffman, 1972a). The rituals that surround these exchanges situate actors in role (Goffman, 1972b). These roles are accompanied by rules of enactment, which demarcate and offer status: affecting who communicates, what is said and, therefore, what is considered appropriate (and legitimate) knowledge to be transferred (Larson, 1979). By foregrounding the micro-sociology of a professional workplace, this research helps us better understand the impact of professionalism on the rules of enactment within and between workspaces and, specifically, the way in which ICT impacts on the transfer of knowledge in 'appropriate' professional interactions. 
In this study, ICT both assisted and impaired knowledge transfer. Following their move to the open plan office participants spoke of colleagues, who were once fellow actors, as if in the role of audience. As such, the display of back region activities - rehearsals and training - were considered as inappropriate, restricting 'accidental' knowledge transfer. However, ICT was used to create back regions where the exchange of knowledge, typically purposive knowledge, took place. Though, the regions were hierarchical and the result was the impairment of intergrade communication and the continuation of status differentiation. Yet, amongst budget managers and project partners, the accountants' considered their knowledge was offered legitimacy when demonstrated through ICT. In these interdisciplinary settings, the abstractness of the accounting profession's established knowledge was made real through its responsiveness to the complexity of service delivery. Thus, through the ICT interface, knowledge of the profession, and the professional, became 'really professional' (Fiona), which assisted knowledge transfer, albeit one-way. In this regard, the professional interactional framework was appropriate: the face needs of all parties were met, highlighting the ability of professionals to professionalise while holding onto their interests (Faulconbridge and Muzio, 2008).

However when communicating with colleagues through ICT, specifically email, the enactment of professional roles and nature of the interactional framework altered, potentially limiting knowledge transfer. In examining this 'tricky' issue, it is useful to draw on Goffman's work to stress the social, but also political, nature of personal interaction; and emphasise the challenge for ICT-mediated communication to support the often fine distinctions. The nuanced nature of communication stems from the difference between a message's locutionary content (the actual statement and its ostensible meaning) and the illocutionary force (its intended meaning). By its very nature, the ICT interface intervenes between the locutionary and illocutionary and the inherent distinctions, which can be played out in verbal communication, are sometimes lost in this space.

Ambiguities are integral to verbal communication; the resultant interplay produces the interactional framework and realises the appropriate rules of response and reply (Goffman, 1981). Purposeful ambiguities draw on this interaction ritual, as can be seen if we refer back to Hugo's 'tricky problem'. In the purposeful ambiguity of a speaker's dodge the more obscure the speaker's statement, the more the hearer is required to use his or her knowledge to bring clarity to the speaker's statement before responding. As such, the sense of the original statement is made in the reply and with it orderly communication is reinstated and knowledge transferred, but across roles - from 'hearer' to 'speaker'. These shifting roles are inherent in 
verbal communication. Importantly, purposeful ambiguities allow interactants to continue an appropriate exchange where there exists a difference in background, history and knowledge, without losing face (Goffman, 1971; 1972b; 1981). Thus, speaker's dodges underpin the growth and propagation of knowledge. However, it is the relative level of dis-attention in verbal communication that supports these approaches and reflects the fleeting nature of speech, mechanisms that are not replicated through text across the ICT interface.

Using Goffman's interactional framework has provided a useful lens through which to examine professional interaction at PACT; furthermore, it offers another dimension when looking at prior research. In their recent study of communication amongst ICT professionals, Trusson and colleagues (2014:365) found that the workers shared knowledge verbally but not in text. They argued that the workers' knowledge 'did not readily lend itself to language, let alone written language'. In another study, the difficulty of portraying the complexity of knowing in a written form was highlighted by Lai and Burchell (2008); they noted that ICT was used for sharing new ideas rather than existing knowledge, which arguably is more nuanced and (maybe?) 'tricky'.

Sitting alongside this work, what is argued here is that the notion of 'looking like a professional' and 'demonstrating professionalism', also has the potential to impair the transfer of knowledge between colleagues. The layout of the workspace, functionality of the ICT architecture and the nature of the interface play an important role, but it is further challenged by the theatrics of the professional workplace (Dent and Whitehead, 2002) and the relative 'success' of the process of inculcation into a professional community of practice. This study reflects the experiences of one community of practitioners: public sector accountants in the UK in a period of financial austerity. As such, the context, timing and restriction to a specific group, along with the sample size, needs to be taken into account in considering the emergent themes. Yet, the findings of this research shed light on issues that are likely to resonate with other professional groups, and those occupations seeking to professionalise. Indeed, the 'professional project' has seen more workers concerned with impressions, of covering and hoping to pass (Goffman, 1959) for a legitimate member of the community (Evetts, 2013). As a result, the performativity of professionalism is likely to be a growing issue.

Given professional firms' reliance on the propagation of knowledge, this study highlights that when considering workspaces, along with issues of connectivity, organisations need to consider how they represent what is an appropriate show of professionalism. Specifically in relation to ICT, work and employment, the key issue to emerge from this research is that any 
reconfiguration of workspaces, and of ICT to traverse workplaces, must address workers' willingness to use it in light of the firm's portrayal of what it is to look professional. 


\section{References}

Abbott, A. (1988), The System of Professions: An Essay on the Division of Expert Labor (Chicago, IL: University of Chicago Press).

Addicott, R., G. McGivern and E. Ferlie (2007), 'The Distortion of a Managerial Technique? The Case of Cancer Networks', British Journal of Management 18, 1, 93-105.

Anderson-Gough, F., C. Grey and K. Robson (2000), 'In the Name of the Client: The Service Ethic in Two Professional Services Firms', Human Relations 53, 9, 1151-1174.

Baldry, C. and A. Barnes (2012), 'The Open-Plan Academy: Space, Control and the Undermining of Professional Identity', Work, Employment and Society 26, 2, 228-245.

Baruch, Y. (2000), 'Teleworking: Benefits and Pitfalls as Perceived by Professionals and Managers', New Technology, Work and Employment 15, 1, 34-49.

Bernstein, E. S. (2012), 'The Transparency Paradox: A Role for Privacy in Organizational Learning and Operational Control', Administrative Science Quarterly 57, 2, 181-216.

Blackler, F. (1993), 'Knowledge and the Theory of Organizations: Organizations as Activity Systems and the Reframing of Management', Journal of Management Studies 30, 6, 863884.

Bosch-Sijtsema, P. M., V. Ruohomäki and M. Vartiainen (2010), 'Multi-Locational Knowledge Workers in the Office: Navigation, Disturbances and Effectiveness', New Technology, Work and Employment 25, 3, 183-195.

Boussebaa, M., A. Sturdy and G. Morgan (2014), 'Learning from the World? Horizontal Knowledge Flows and Geopolitics in International Consulting Firms', International Journal of Human Resource Management 25, 9, 1227-1242.

Brown, B. and K. O'Hara (2003), 'Place as a Practical Concern of Mobile Workers', Environment and Planning A 35, 9, 1565-1587.

Brown, J. S. and P. Duguid (1991), 'Organizational Learning and Communities of Practice: Toward a Unified View of Working, Learning, and Innovating', Organization Science 2, 1, 40-57.

Dent, M. and S. Whitehead (eds.) 2002. Managing Professional Identities: Knowledge, Performativity and the 'New' Professional, (London: Routledge).

Donnelly, R. (2011), 'The Ambiguities and Tensions in Creating and Capturing Value: Views from HRM Consultants in a Leading Consultancy Firm', Human Resource Management 50, 3, 425-440.

Durkheim, E. (1957), Professional Ethics and Civic Morals (London: Routledge and Kegan Paul).

Empson, L. (2001), 'Fear of Exploitation and Fear of Contamination: Impediments to Knowledge Transfer in Mergers between Professional Service Firms', Human Relations 54, 7, 839-862.

Evetts, J. (2013), 'Professionalism: Value and Ideology', Current Sociology 61, 5-6, 778-796.

Faulconbridge, J. and D. Muzio (2008), 'Organizational Professionalism in Globalizing Law Firms', Work, Employment and Society 22, 1, 7-25.

Felstead, A., N. Jewson, A. Phizacklea and S. Walters (2002), 'The Option to Work at Home: Another Privilege for the Favoured Few?', New Technology, Work and Employment 17, 3, 204-223.

Felstead, A., N. Jewson and S. Walters (2003), 'Managerial Control of Employees Working at Home', British Journal of Industrial Relations 41, 2, 241-264.

Felstead, A., N. Jewson and S. Walters (2005), Changing Places of Work (London: Palgrave). Fournier, V. (1999), 'The Appeal to 'Professionalism' as a Disciplinary Mechanism', Social Review 47, 2, 280-307. 
Fox, S. (2000), 'Communities of Practice, Foucault and Actor-Network Therory', Journal of Management Studies 37, 6, 853-868.

Freidson, E. (2001), Professionalism: The Third Logic (Cambridge: Polity Press).

Goffman, E. (1955), 'On Face-Work: An Analysis of Ritual Elements in Social Interaction', Journal for the Study of Interpersonal Processes 18, 3, 213-231.

Goffman, E. (1959), The Presentation of Self in Everyday Life (London: The Penguin Press).

Goffman, E. (1963a), Behavior in Public Places: Notes on the Social Organization of Gatherings (New York: The Free Press).

Goffman, E. (1963b), Stigma: Notes on the Management of a Spoiled Identity (London: The Penguin Press).

Goffman, E. (1971), Relations in Public: Microstudies of the Public Order (London: The Penguin Press).

Goffman, E. (1972a), Encounters: Two Studies in the Sociology of Interaction (London: The Penguin Press).

Goffman, E. (1972b), Interaction Ritual: Essays on Face-to-Face Behaviour (London: The Penguin Press).

Goffman, E. (1981), Forms of Talk (Philadelphia: University of Pennsylvania Press).

Goode, W. J. (1957), 'Community within a Community: The Professions', American Sociological Review 22, 2, 194-200.

Haas, M. R. and S. Park (2010), 'To Share or Not to Share? Professional Norms, Reference Groups, and Information Withholding among Life Scientists', Organization Science 21, 4, 873-891.

Halford, S. (2005), 'Hybrid Workspace: Re-Spatialisations of Work, Organisation and Management', New Technology, Work and Employment 20, 1, 19-33.

Hazlett, S.-A., R. McAdam and S. Gallagher (2005), 'Theory Building in Knowledge Management: In Search of Paradigms', Journal of Management Inquiry 14, 1, 31-42.

Hislop, D. (2002), 'Mission Impossible? Communicating and Sharing Knowledge Via Information Technology', Journal of Information Technology 17, 3, 165-177.

Ibarra, H. (1999), 'Provisional Selves: Experimenting with Image and Identity in Professional Adaptation', Administrative Science Quarterly 44, 4, 764-791.

Johnson, T. J. (1972), Professions and Power (London: Palgrave Macmillan).

Kiesler, S. and J. N. Cummings 2002. What Do We Know About Proximity and Distance in Work Groups? A Legacy of Research, in P. Hinds and S. Kiesler (eds) Distributed Work. (London: MIT Press), pp. 76-109.

Kurland, N. and T. Egan (1999), 'Telecommuting: Justice and Control in the Virtual Organization', Organization Science 10, 4, 500-513.

Lai, Y. and B. Burchell (2008), 'Distributed Work: Communication in an 'Officeless Firm", New Technology, Work and Employment 23, 1-2, 61-76.

Larson, M. S. (1979), The Rise of Professionalism: A Sociological Analysis, (Berkeley: University of California Press).

Lave, J. and E. Wenger (1991), Situated Learning (Cambridge: Cambridge University Press).

Leonardi, P. M. and S. R. Barley (2008), 'Materiality and Change: Challenges to Building Better Theory About Technology and Organizing', Information and Organization 18, 3, 159-176.

Marans, R. W. and K. F. Spreckelmeyer (1982), 'Evaluating Open and Conventional Office Design', Environment and Behavior 14, 3, 333-351.

Marks, A. and D. Scholarios (2007), 'Revisiting Technical Workers: Professional and Organisational Identities in the Software Industry', New Technology, Work and Employment 22, 2, 98-117. 
McAdam, R. and S. McCreedy (2000), 'A Critique of Knowledge Management: Using a Social Constructionist Model', New Technology, Work and Employment 15, 2, 155-168.

Miles, M. B. and A. M. Huberman (1994), Qualitative Data Analysis (Thousand Oaks, CA, Sage Publications).

Navis, C. and M. A. Glynn (2010), 'How New Market Categories Emerge: Temporal Dynamics of Legitimacy, Identity, and Entrepreneurship in Satellite Radio, 1990-2005', Administrative Science Quarterly 55, 3, 439-471.

Nonaka, I. and H. Takeuchi (1995), The Knowledge-Creating Company-How Japanese Companies Create the Dynamics of Innovation (New York, Oxford University Press).

Orlikowski, W. J. (2002), 'Knowing in Practice: Enacting a Collective Capability in Distributed Organizing', Organization Science 13, 3, 249-273.

Paton, S., D. Hodgson and D. Muzio (2013), 'The Price of Corporate Professionalisation: Analysing the Corporate Capture of Professions in the UK', New Technology, Work and Employment 28, 3, 227-240.

Pinch, T. J. and W. E. Bijker (1984), 'The Social Construction of Facts and Artefacts: Or How the Sociology of Science and the Sociology of Technology Might Benefit Each Other', Social Studies of Science 14, 3, 399-441.

Pratt, M. G., K. W. Rockmann and J. B. Kaufmann (2006), 'Constructing Professional Identity: The Role of Work and Identity Learning Cycles in the Customization of Identity among Medical Residents', Academy of Management Journal 49, 2, 235-262.

Robertson, M. and J. Swan (1998), 'Modes of Organizing in an Expert Consultancy: A Case Study of Knowledge, Power and Egos', Organization 5, 4, 543-564.

Ruiz, Y. and A. Walling (2005), 'Home-Based Working Using Communications Technologies', Labour Market Trends 113, 10, 417-426.

Scott, W. R. (2008), 'Lords of the Dance: Professionals as Institutional Agents', Organization Studies 29, 2, 219-238.

Star, S. L. and J. R. Griesemer (1989), 'Institutional Ecology, "Translations” and Boundary Objects: Amateurs and Professionals in Berkeley's Museum of Vertebrate Zoology, 190739', Social Studies of Science 19, 3, 387-420.

Suddaby, R., Y. Gendron and H. Lam (2009), 'The Organizational Context of Professionalism in Accounting', Accounting, Organizations and Society 34, 3-4, 409-427.

Suddaby, R. and T. Viale (2011), 'Professionals and Field-Level Change: Institutional Work and the Professional Project', Current Sociology 59, 4, 423-442.

Swan, J., H. Scarbrough and M. Robertson (2002), 'The Construction of 'Communities of Practice' in the Management of Innovation', Management Learning 33, 4, 477-496.

Trusson, C. R., N. F. Doherty and D. Hislop (2014), 'Knowledge Sharing Using It Service Management Tools: Conflicting Discourses and Incompatible Practices', Information Systems Journal 24, 4, 347-371.

Van Maanen, J. and E. G. Schein (1979). Toward a Theory of Organizational Socialization, in B. M. Staw and L. Cummings (eds) Research in Organizational Behavior. (Greenwich, CT: JAI Press), pp. 209-264.

Wenger, E. (1998), Communities of Practice: Learning, Meaning, and Identity (Cambridge, Cambridge University Press).

Whittle, A. and F. Mueller (2009), 'I Could Be Dead for Two Weeks and My Boss Would Never Know': Telework and the Politics of Representation', New Technology, Work and Employment 24, 2, 131-143.

Zalesny, M. D. and R. V. Farace (1987), 'Traditional Versus Open Offices: A Comparison of Sociotechnical, Social Relations, and Symbolic Meaning Perspectives', Academy of Management Journal 30, 2, 240-259. 
Zuboff, S. (1988), In the Age of the Smart Machine: The Future of Work and Power (New York: Basic Books). 